\title{
Geodynamical interpretation of crustal and upper mantle electrical conductivity anomalies in Sayan-Baikal province
}

\author{
A. M. Popov, A. I. Kiselev, and V. V. Mordvinova \\ Institute of the Earth's Crust, Russian Academy of Sciences, Irkutsk, Russia
}

(Received November 16, 1998; Revised April 12, 1999; Accepted April 12, 1999)

\begin{abstract}
There exists a number of models that account for the deep structure of the Sayan-Baikal province on the basis of different geophysical data. The models based on magnetotelluric soundings differ from those obtained from seismology with no regard to magnetotelluric soundings (MTS) results. To decide between the active and passive mechanisms of Baikal rifting, we propose to correlate the modeling results to the available seismological and petrological data, as well as to the model of asthenospheric diapirism put forward by Zorin et al. (1989, 1990, 1995). Inasmuch as the reality of MTS-based models depends on removal of static-shift effects, the reported threedimensional modeling of the Baikal rift deep structure was preceded by normalization of the original MT curves by the global magnetovariation curve. The enhanced electrical conductivities of the crust and upper mantle of the region is interpreted in terms of geodynamics where the Cenozoic activity is suggested to be driven by convective mantle flow and triggered by the associated plate collisions. The origin and evolution of the Baikal rift can be explained in terms of reactivation of a pre-existing lithospheric inhomogeneity between the Siberian craton and the Sayan-Baikal fold area.
\end{abstract}

\section{Introduction}

Enhanced electrical conductivities in the deep crust of the Baikal region, as well as elsewhere in the world (Jones, 1992; Simpson, 1998; and references therein), have been attributed to water-saturation, brittle-ductile transitions, or graphitization. The wide range of the possible causes can be constrained if regard the well-known regularity that crustal conductors are shallower and better pronounced in tectonically active regions than in stable areas. So it appears reasonable to consider the sources of the anomalies in terms of geodynamics.

A geodynamical model of the Baikal rift zone, put forward by Zorin et al. (1995), is based on the concept of an asthenospheric diaper with its top reaching the crustal base (at 37 to $50 \mathrm{~km}$ ) beneath the rift. Under neighbouring stable regions the asthenospheric surface is situated at a depth over $100 \mathrm{~km}$. Evidently, rifting was causally related with the development of such upwellings. The authors suppose that the asthenospheric material mechanically replaces lithosphere along weak zones: blocks are detached from the lithosphere and sink into the asthenosphere. Plastic flow in the solid part of the mantle is of secondary importance. The authors simulated this replacement through an upward movement of the $1200^{\circ} \mathrm{C}$ isotherm (temperature of mantle solidus) (Zorin et al., 1989, 1990, 1995).

This model contradicts the 3D inversion model induced from MT soundings. Following other researches, two conductive layers are distinguished: i) the mid- and low-crustal and ii) the mantle one, with the layer surface uplifted from

Copy right(c) The Society of Geomagnetism and Earth, Planetary and Space Sciences (SGEPSS); The Seismological Society of Japan; The Volcanological Society of Japan; The Geodetic Society of Japan; The Japanese Society for Planetary Sciences.
100-110 km depth in the southern Baikal rift zone to 60-70 $\mathrm{km}$ northeastwards along the eastern Baikal coast. The top of this layer seems to correspond to the asthenospheric roof (Popov, 1989, 1990; Popov et al., 1991) (Figs. 1 and 2). The MTS inversion was preceded by normalization of raw resistivity curves against the global magnetovariation curve in order to remove static-shift effects. In doing this we based on seismic and electromagnetic data from the study region that attest to proximity of electrical conductivity at depths below $300 \mathrm{~km}$ of the global average (Vanyan et al., 1980). The two models differ so dramatically that may lead to two endmembers of possible mechanisms of continental rifting, the active (the former model) and the passive (the latter model) ones. Berdichevsky et al. (1998) were also agree with the same idea of depths of the asthenosphere. To decide between the two alternatives we propose to compare the available data from different geophysical methods.

\section{On the Nature of Electrical Conductivity Anomalies in the Crust}

Graphite model. Sulphide and carbon occur among the Precambrian rocks of the Sayan-Baikal mountain province in sporadic lenses a few tens or a few hundred meters thick and therefore hardly can exert an extensive effect on crustal electrical conductance. On regional scale, low-grade metamorphics contain carbon as a diffuse uniformly saturating matter. In higher grade granular rocks it fills in pores and small cracks sometimes forming isolated lenses. The content of carbon in metasediments is in a range of 0.5 to $0.8 \mathrm{wt} \%$, varying from $0.06 \%$ in graphitic gneiss schists to $0.38 \%$ in coaliferous black shales in the Olkhon Island, being $0.52 \%$ in graphitic shales near the southern tip of Lake Baikal, and 


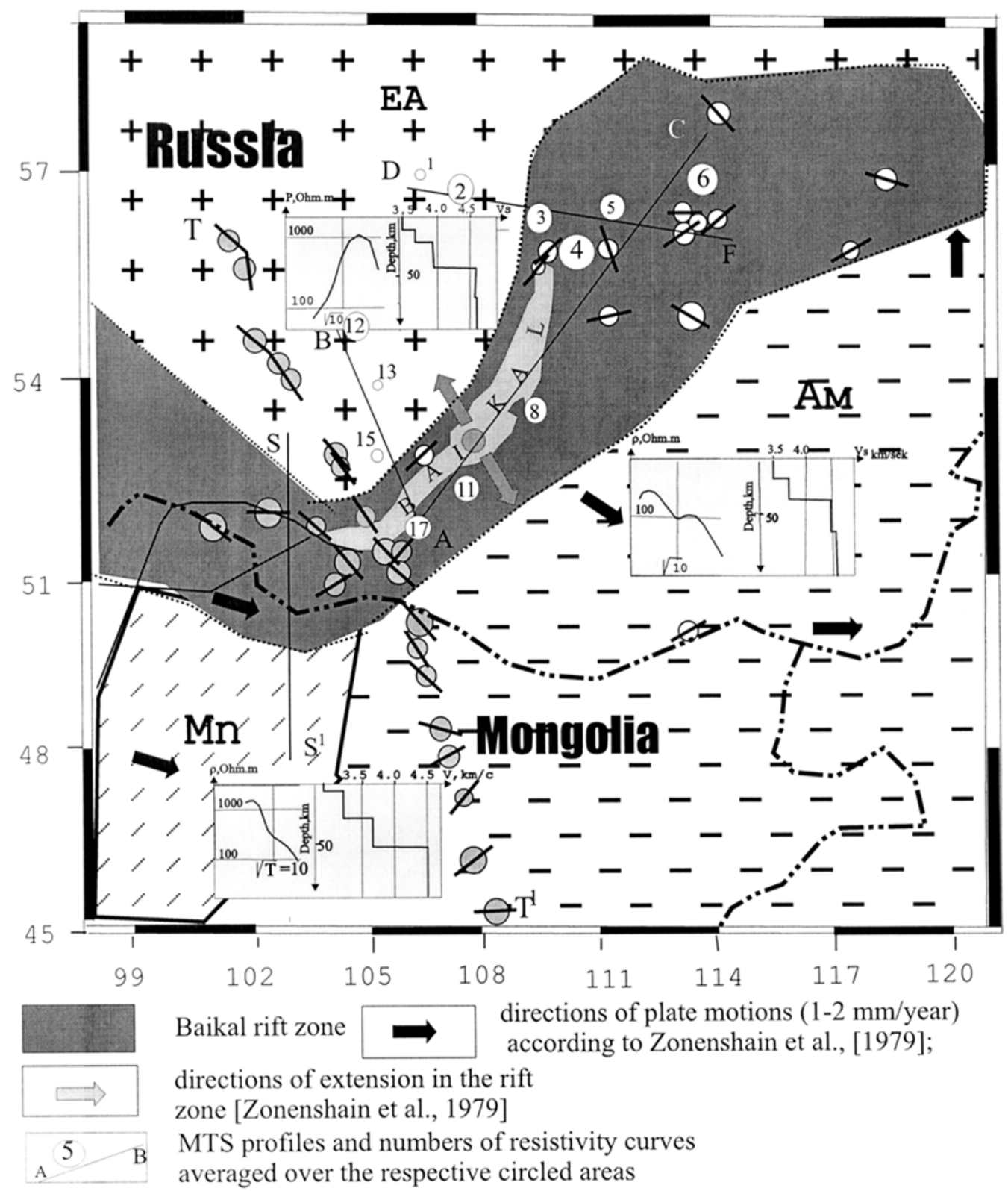

Fast directions and splitting times, afte Gao et al., 1994; (profile T-T)

\section{$0.5,1.0,1.5,2.0 \mathrm{~s}$}

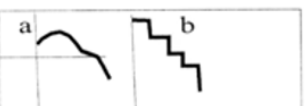

typical MT curves (a) and S-wave seismic velocity profile after(b)

[Kozhevnikov, 1987]

Fig. 1. Generalised geodynamics of Central Asia and locations of MTS profiles and seismic stations from teleseismic tomgraphy experiment. $1=$ Baikla rift zone; 2 = directions of plate motions (1-2 mm/year) according to Zonenshain et al. (1979); $3=$ direction of extension in the rift zone (Zonenshain et al., 1979); 4 = MTS profiles and numbers of resistivity curves averaged over the respective circled areas; $5=$ fast directions and splitting times, after (Gao et al., 1994); 6 = typical MT curves (a) and S-wave seismic profile after (Kozhevnikov, 1987). Abbreviations stand for plate names: EA = Eurasian plate, $\mathrm{MN}=$ Mongolian plate, $\mathrm{AM}=$ Amur plate, $\mathrm{SS} 1$ = seismic profile (Kopnichev, 1992).

$0.89 \%$ in the graphitic shales of Aldan (eastern termination of the Baikal rift zone) (Sidorenko and Sidorenko, 1975). Such a low content of carbon and sulphide, as well as small thickness of graphitic rocks cannot enable interconnected conductive netwroks. Moreover, being reworked by repeated metasomatism, the graphitized minerals in Precambrian metasediments and mafic complexes became disintegrated into small silicic-coated grains or thin isolated interbeds that made the rock higher resistive. At the same time, carbon can cause a stronger enhancing effect on conductivity when existing as a mobile element in rock-saturating fluids.

Fluid model. Interpretation of seismic reflection data (Zverev and Kosminskaya, 1980; Nikolaevsky, 1986; Nikolaevsky and Sharov, 1986; Shchukin, 1986; Pavlenkova, 


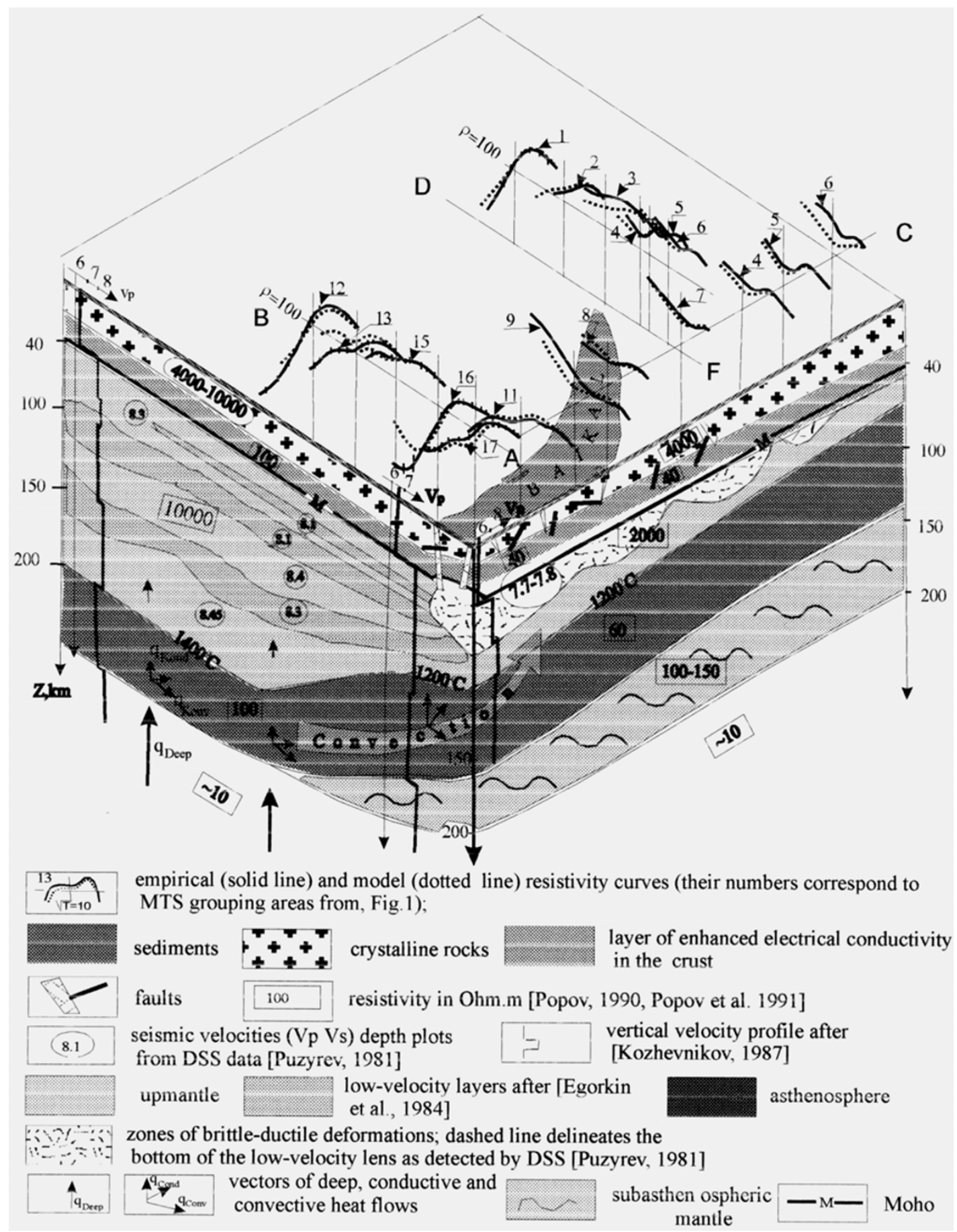

Fig. 2. Block-diagram of geodynamics and deep structure of the contact zone between the Siberian Platform and the Sayan-Baikal fold area. $1=$ empirical (solid line) and model (dotted line) resistivity curves (their numbers correspond to MTS grouping areas from Fig. 1 ); $2=$ sediments; $3=$ crystalline rocks; $4=$ layer of enhanced electrical conductivity in the crust; $5=$ faults; $6=$ resistivity in Ohm.m (Popov, 1990; Popov et al., 1991 ); $7=$ seismic

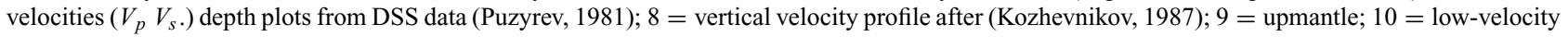
layers after (Egorkin et al., 1984); $11=$ asthenosphere; 12 = zones of brittle-ductile deformations; dashed line delineates the bottom of the low-velocity lens as detected by DSS (Puzyrev, 1981); 13, 14 = vectors of deep, conductive and convective heat flows; $15=$ subasthenospheric mantle; $16=$ Moho.

1996; Pavlenkova and Belousov, 1992) attests to strong seismic layering of the lithosphere. Numerous reflectors, seen in cross-sections as thin clusters of layers with sharply contrasting elastic properties, are nearly vertical in the shallow crust and lower-angle in the middle crust at depths between $10-20 \mathrm{~km}$. The nature of the sub-horizontal interfaces has been discussed by many models claimimg chiefly tectonic (subhorizontal rock failure) or magmatic (intrusion and underplating) origin (Leonov, 1993).

Seismic data from many regions of the world show reflecting horizons of fault origin at depths between 15 and $25 \mathrm{~km}$ or deeper (Fanke et al., 1990). The presence of brittle deformation and mylonitization zones at great depths has been proved by super-deep drilling (Baisarovich et al., 1992). 


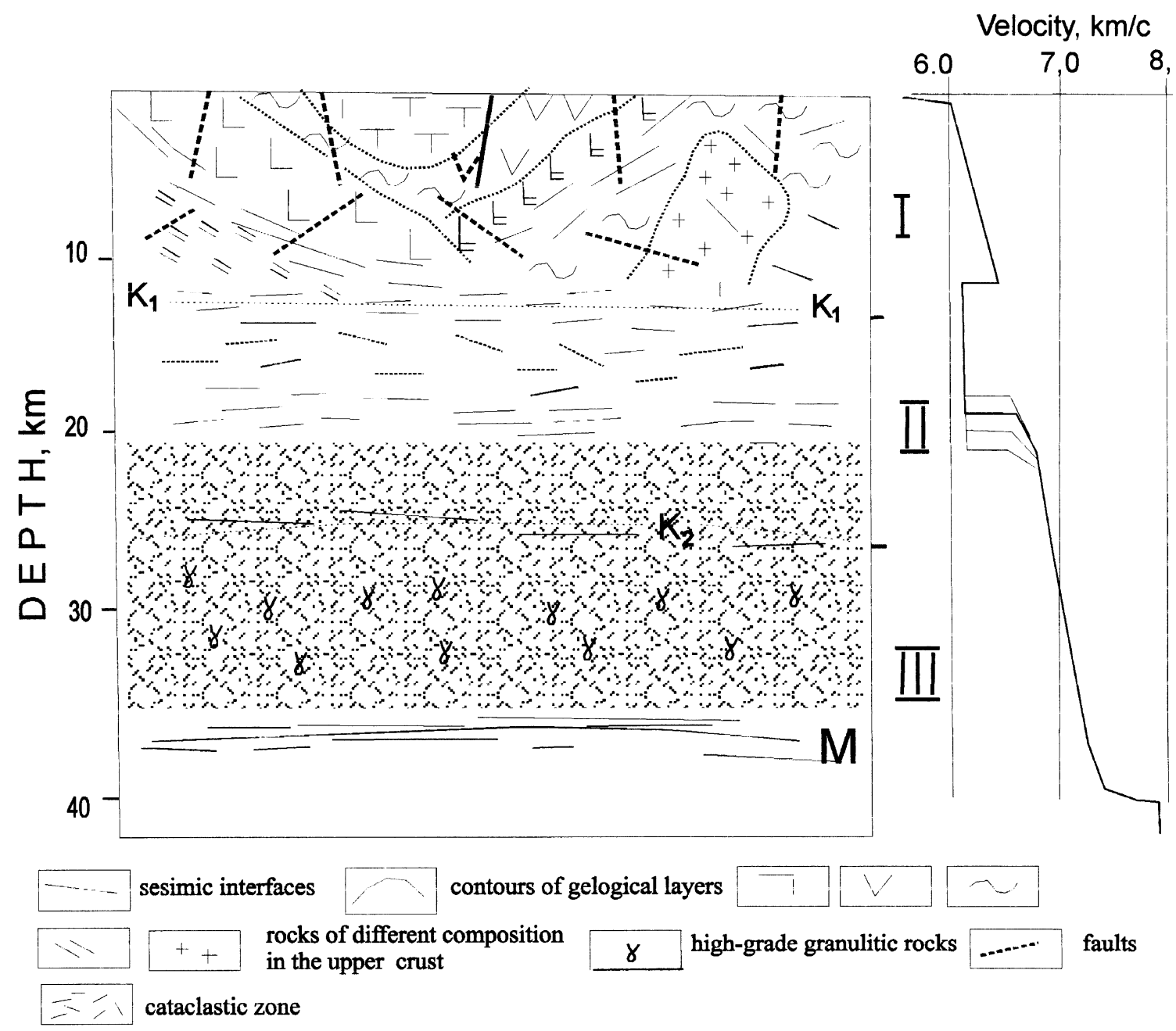

Fig. 3. Generalised model of the continental crust containing a weak intermediate layer. $1=$ seismic interfaces; $2=$ contours of geological layers, 3-7 = rocks of different composition in the upper crust; $8=$ high-grade granulitic rocks; $9=$ faults; $10=$ cataclastic zone. Upper, lower and intermediate layers in the crust separated by boundaries K1 and K2; M = Moho after (Zverev and Kosminskaya, 1980; Nikolaevsky, 1986).

Dense clustering of mid-crustal reflectors indicative of lateral rock displacement is for their tectonic origin because magmatic bodies would produce oblique and additional subhorizontal reflections. The tectonic nature of most reflectors implies great importance of fluids for both geodynamic regime and physical (elastic and conductive) properties of rocks.

Clustering density and depth of reflectors, as well as distribution of other seismic parameters, give preference to the three-layered rather than two-layered model of the crust. See, for instance, Zverev and Kosminskaya (1980) who discriminated three main velocity layers (Fig. 3). The intermediate layer shows strong horizontal lamination, small vertical velocity gradients and low-velocity layers in the depth range of 10 to $20 \mathrm{~km}$, and high transparency of the crust.

Nikolaevsky (1986) and Nikolaevsky and Sharov (1986) attribute the three-layer structure of the crust to rheology transitions and the respective different response of rocks to external tectonic stresses, especially their deviatoric component where increase in lithostatic load not only enhances rock strength (Fyfe et al., 1978) but also changes conditions for brittle failure in the crust. Tectonic stresses create the zones of deep streams with recrystallization of rocks. In the process of recrystallization new grains are formed with the great number of inside defects that encreases their deformability.The observed layering is thus interpreted by variations in vertical-to-horisontal stress relationships, permeability and fluid content in rocks.

\section{Lithosphere-Asthenosphere Interaction and Rifting}

The Cenozoic evolution of the Sayan-Baikal province has been explained in terms of the concept of active rifting and mantle diapirism, according to which there is an asthenospheric diapir beneath the Baikal rift zone, its top reaching the Moho, and asthenosphere is identified as $1200^{\circ} \mathrm{C}$ hot medium containing a molten phase (a hot spot hypothesis) (Zorin et al., 1989, 1990, 1995). The model was based upon deep seismic soundings (DSS), seismological and gravity data, but did not regard the MTS results. Deep seismic soundings showed a drop in P-wave velocities $\left(V_{p}=7.7-\right.$ $7.8 \mathrm{~km} / \mathrm{s}$ ) along the Moho within the Baikal rift (Puzyrev, 1981). Seismological data on arrivals from remote earthquakes (Rogozhina and Kozhevnikov, 1979) revealed an area 


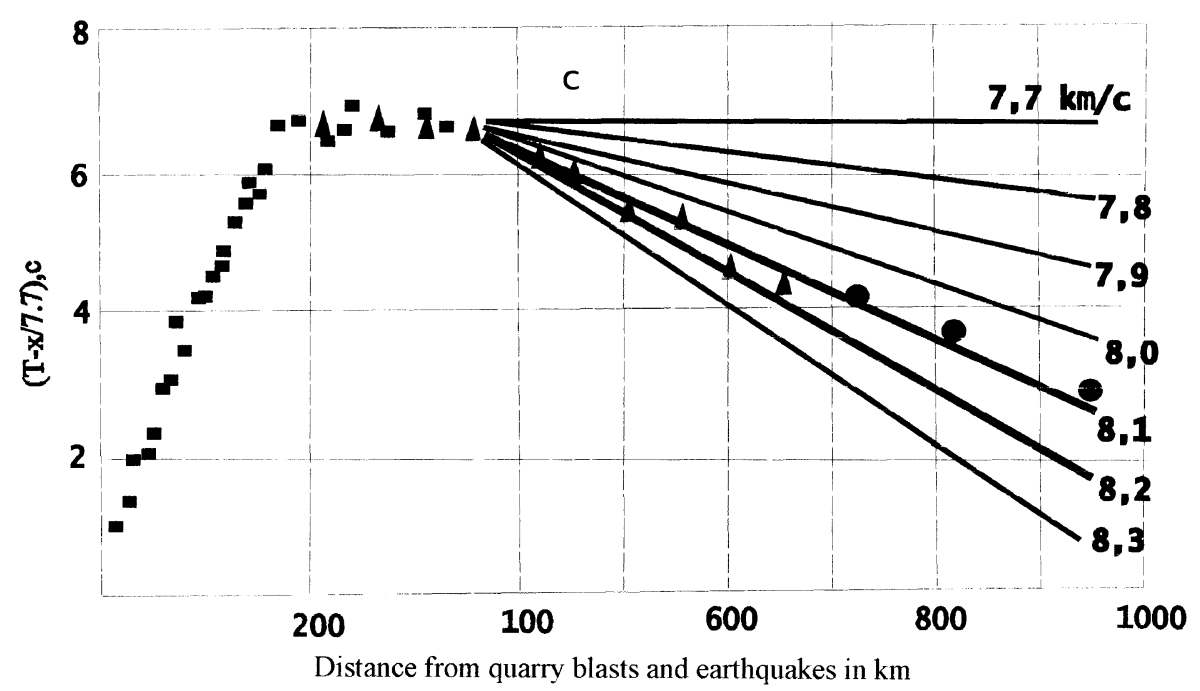

Fig. 4. Synthetic hodograph for quarry blasts and earthquakes (first arrivals). Travel times from DSS data are shown by squares; averaged travel times for 50 and $100 \mathrm{~km}$ intervals of epicentral distances are shown by triangles and bold circles, respectively (Krylov et al., 1974).

of anomalous low-velocity mantle beneath the Sayan-Baikal province. The depth of its top remained poorly constrained because of low resolution of the method, and it might be delineated by the DSS-inferred low boundary velocities on the Moho (Zorin et al., 1989). In this respect an important question comes up, whether it is suitable to put together DSS and seismological data by associating the low Moho velocities (that are attributed to the area of greater extent than the surface expression of rifting (Zorin et al., 1990)) with the top of the anomalous mantle. Another question is whether the low P-wave velocities of 7.7-7.8 $\mathrm{km} / \mathrm{s}$ correspond to partially molten material as a feature of the asthenosphere.

To answer these questions we need to investigate spatial and physical relationships between the anomalous mantle revealed by Rogozhina and Kozhevnikov (1979) and the lowvelocity lens (Krylov et al., 1974; Puzyrev, 1981). In the latter work it is reported that the low-velocity lens is underlined by a layer of higher velocities and this is reflected in a prominent bend of the synthetic DSS-seismology hodograph for earthquakes and quarry blasts beneath the Baikal rift zone (Fig. 4). The bend comes up because the first arrivals are of head waves traveling from the mantle top at boundary velocities of 7.7-7.8 km/s at epicentral distances within 200 to $350 \mathrm{~km}$ whereas they are the normal-velocity $(8.1 \mathrm{~km} / \mathrm{s})$ waves at greater distances, which are reflected from the rocks underneath the low-velocity lens. The limited thickness of the low-velocity lens is also by distribution of $\mathrm{S}$ waves obtained from teleseismic data along a profile across the southern Baikal rift illustrated (Fig. 5).

The latest results of seismic tomography inversion $\mathrm{P}$-wave (L. Vinnik and V. Mordvinova; private communication) show a slight velocity decrease over the depth range from 40 to $100 \mathrm{~km}$, the departure from normal being about 2\% (7.94 $\mathrm{km} / \mathrm{s}$ against $8.1 \mathrm{~km} / \mathrm{s}$, that is a velocity typical of peridotite). Nearly the same P-wave velocities $(7.9 \mathrm{~km} / \mathrm{s})$ is suggested from a synthetic hodograph of Krylov et al. (1974) and Puzyrev (1981) at the velocity decrease zone.

Attenuation measurements in the Baikal rift mantle
(Kopnichev, 1992) showed an extremely inhomogeneous absorption field, even within a narrow strip immediately along the rift axis. The mean absorption of the S-waves abruptly drops towards the north-eastern segment of the rift zone (see profile $\mathrm{SS}^{1}$ Fig. 1) and attenuation rate varies both vertically and horizontally. There is a high absorption layer contacting the crustal base that is underlain in the central part of the rift by low-absorption rocks. The high absorptive layer spatially coincides with the low-velocity lens detected by DSS data and has the same thickness. The high Q-factor and lowabsorption layer is underlain by another high absorption one in the uppermost mantle throughout the study region (Fig. 6) (Kopnichev, 1992). The latter coincides with a layer of enhanced electrical conductivity which apparently is attributed to the asthenosphere. Therefore, the uppermost mantle is uneven in elastic properties and the low-velocity lens exists as an isolated body.

The other critical question is possibility of partial melt can be elucidated if analyze the physic state of the material of the low-velocity lens. Accoding to the available data it appears doubtful that its nature were related to partial melting. The reasons are that firstly, MTS-obtained electrical resistivity of rocks beneath the crustal base of the Baikal rift (2000 Ohm.m) (Popov, 1989) rules out both partial melting and heating over $800^{\circ} \mathrm{C}$, as shown by laboratory experiments and supported by tomography results that evidence of an upwarp of the $900^{\circ} \mathrm{C}$ isotherm to a depth of $50 \mathrm{~km}$ beneath the rift. Second, a lens cannot exist in the partially molten state for millions of years but must crystallize in a few thousand years. Third, teleseismic tomography data (Vinnik et al., 1997) show a drop of upper mantle velocities beneath the rift zone but do not suggest existence of molten material in the anomalous area till a depth of $100 \mathrm{~km}$. The $V_{p} / V_{s}$ ratios at this depth range are 1.7-2.0 corresponding to the theoretical value associated with compositional variations of 1.7. and significantly smaller than that of (not with those due to) temperature variations (2.4) and partial melting (3.9) (Vinnik et al., 1997). The observed ratios of 1.7 to 2.0 can indicate some 


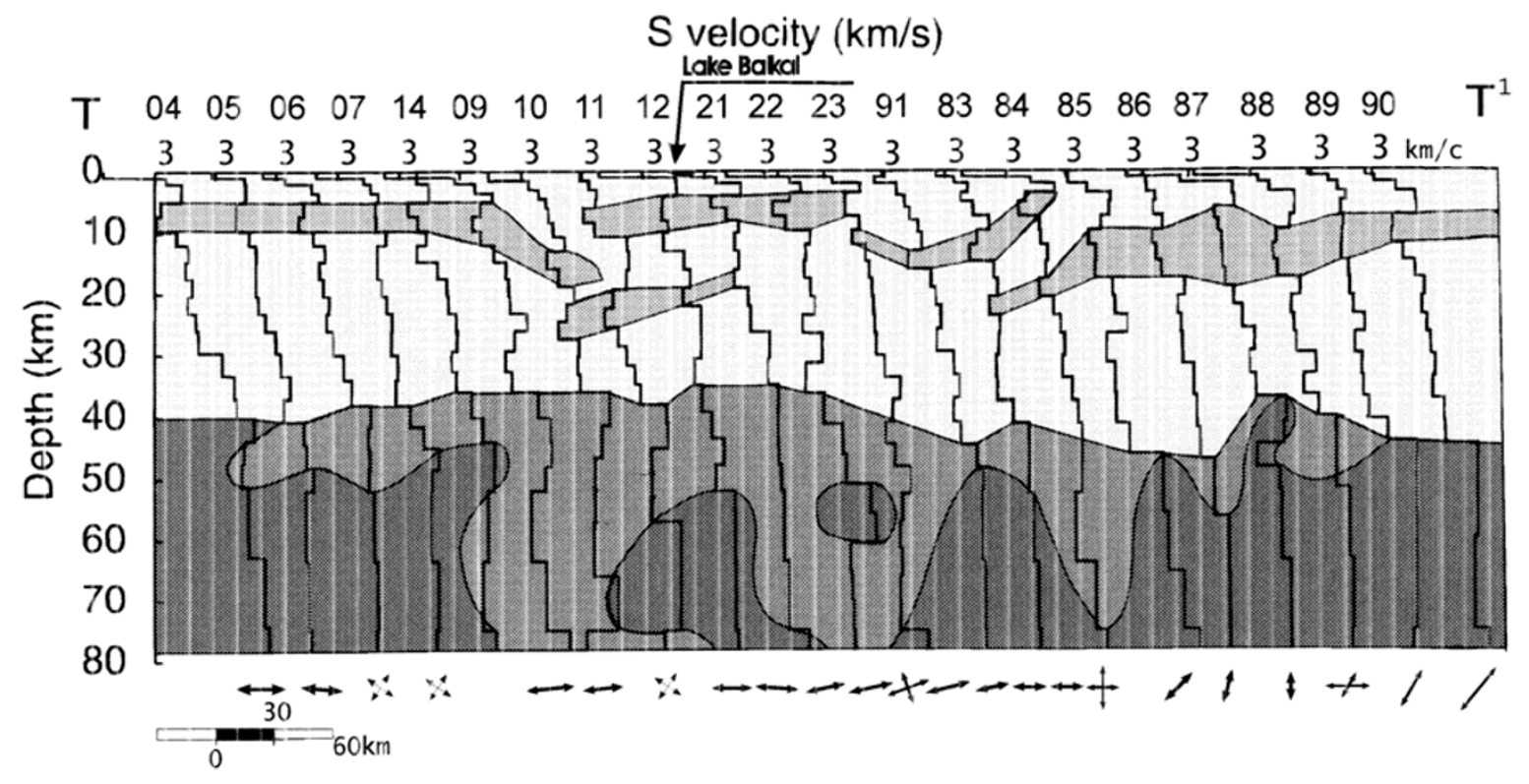

Fig. 5. Generalised S-velocity distribution obtained due to inversion of teleseismic data on the profile across the southern Baikal rift zone TT' (Fig. 1). Velocity distributions from each seismograph are spaced at $1 \mathrm{~km} / \mathrm{s}$ on the velocity axis; the rightward direction corresponds to the NNW-SSE direction of the profile. Velocity at each station is shown on the bias of $3 \mathrm{~km} / \mathrm{s}$ (shown as " 3 " under the station numbers). The scheme does not intend to be a velocity map but to show features of deep structure at transitions from station to station and from one tectonic unit to another. Bold line delineates the crust-mantle boundary. Light-grey field traces low-velocity layers in the crust (fragments) and upper mantle; dark-grey field covers normal velocities in the upper mantle. The directions of the needles below the figure correspond to the fast directions (Gao et al., 1994) and their length is proportional to the value of splitting times.

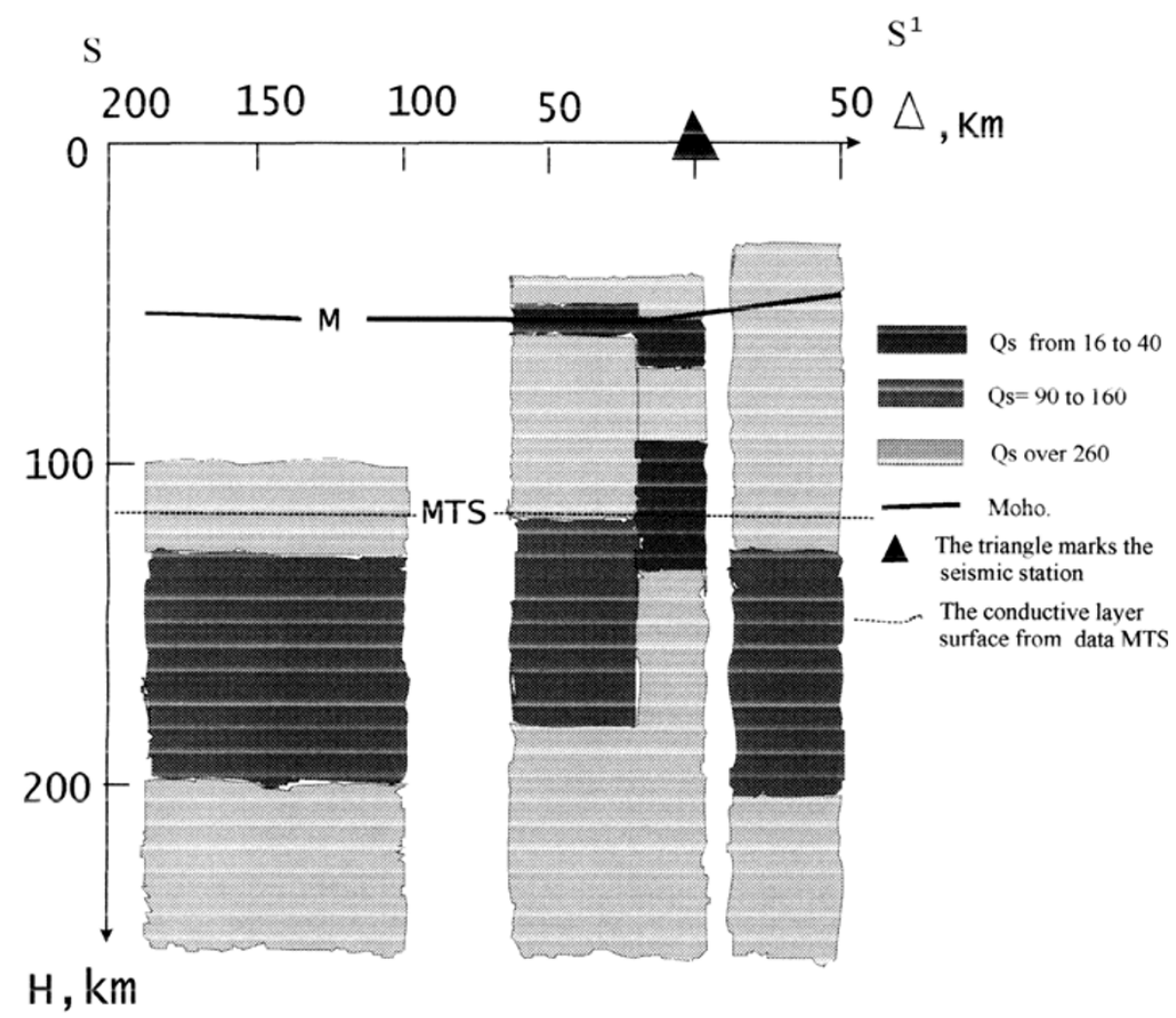

Fig. 6. Vertical cross-section of the lithosphere and asthenosphere of the south-western segment of the rift, obtained from wave absorption data on the profile AA'; $1=Q_{s}$ from 16 to $40 ; Q_{s}=$ from 90 to $160 ; 3=Q_{s}$ over 260; $4=$ Moho. The triangle marks the seismic station (Kopnichev, 1992). 
heating but never partial melting anyway. Fourth, (Gao et $a l .$, 1997) showed that the mantle must contain practically no melt immediately beneath the Baikal rift whereas beneath the East African rift partial melt must make up 2-3\% and possibly a fraction of percent beneath the Rio Grande rift. This conclusion was achieved proceeding from estimates of temperature-dependent $\mathrm{P}$-wave velocities and attenuation in mantle rocks during studies of polarization anizotropy by SKS splitting measurements in the continental rifts of Baikal, East Africa and Rio Grande, in comparison to tomographic results from the three rifts. The authors also report that Pwave velocity perturbations caused by low-velocity anomalies in the uppermost mantle beneath the three rifts are $12 \%$, $8 \%$ and 5\% for the East African, Rio Grande and Baikal rifts, respectively (Gao et al., 1997). Fifth, petrology of mantle xenoliths from basalts attests that the lithosphere beneath the Baikal rift has never been completely replaced by the asthenosphere (Kiselev and Popov, 1992). Mantle xenoliths drawn to the surface by basaltic eruptions in different parts of the rift bear evidence of thermal and compositional heterogeneity of the underlying mantle. The most widely spread are spinel lherzolites that give way to garnet varieties downsection. Two-pyroxene thermometry showed that equilibrium temperatures of pyroxenes in the spinel lherzolites of the Baikal rift zone and its surroundings vary mainly between 900 and $1100^{\circ} \mathrm{C}$ (Kiselev and Popov, 1992) whereas for garnet lherzolites from greater depths $(\mathrm{P}=23-27 \mathrm{kbar})$ the variations are within $1150-1190^{\circ} \mathrm{C}$. Such a broad range apparently reflects both vertical and lateral thermal and compositional heterogeneity of the upper mantle at depths between 45 and $75 \mathrm{~km}$.

Therefore, partial melting in the low-velocity lens, i.e. the upwarp of the $1200^{\circ} \mathrm{C}$ isotherm representing the "active" asthenosphere (as a layer involving partially molten material) to the crustal base is not supported by most geophysical and petrological data.

\section{A Plume or Excitated Asthenosphere (an As- thenospheric Upwarp)?}

As mentioned above, the low-velocity zone was scanned by seismic tomography (Vinnik et al., 1997) till $250 \mathrm{~km}$ below the surface, and the departure of P-wave velocities from the standard hodograph was found to be $4 \%$ the greatest $(7.8-$ 7.9 against $8.1-8.2 \mathrm{~km} / \mathrm{s}$ ) at a depth of about $100-150 \mathrm{~km}$; below $150 \mathrm{~km}$ the velocities are higher. Note that at a depth $100-110 \mathrm{~km}$ coincides with that of the surface of conductive layer according to magnetotelluric soundings. Zhang and Tanimoto (1993) report the presence of extensive zones of prominent velocity drop in nearly all active regions that may involve a mantle hot spot (at a depth of about 50-200 km), but not beneath the Baikal rift where the S-wave velocities are normal or nearly normal in contrast to the higher ones below the adjacent Siberian Platform. Analysis of converted wave shapes and travel times in course of the same experiment (Vinnik et al., 1997) did not show contrasts of the rift against the neighboring stable areas; moreover thickness of the phase transition zone of the rocks beneath the rift, which is temperature sensitive at depths from 410 to $650 \mathrm{~km}$ showed to be nearly normal. No contrasting low $\mathrm{S}$-wave velocity zones have been detected by teleseismic tomography either.

\section{Discussion}

Seismoelectric model of the crust of the Baikal region. The three seismic layers with different rheology can be considered in terms of electrical conductivity variations. The uppermost layer, about $10 \mathrm{~km}$ thick, involves nearly vertical and oblique faults. In this case fault tectonics cannot cause a significant effect on the overall electrical conductivity and merely produces a more complex block structure of the cross-section. Even if fluids do circulate along such faults no interconnected conductive network can be created. Therefore, in those cases the shallow crust electrical conductivity depends mainly on rock composition.

In the intermediate layer, between 10 and $20 \mathrm{~km}$ deep, faults are nearly horizontal. The layer characteristically involves stick-slip motions, causing earthquakes, especially in its upper part, near the K-1 boundary (Sibson, 1977). The presence of subhorizontal fault and strike-slip faults in this part of the crust explains the existence of waveguides (Zverev and Kosminskaya, 1980; Jones and Nur, 1984; Christensen and Szymanski, 1988; Reston, 1988).

The third seismic layer deeper than $20 \mathrm{~km}$ (Fig. 3) with high seismic velocities $\left(V_{p}=6.7-7.7 \mathrm{~km} / \mathrm{s}\right)$ is separated from the intermediate layer by K-2 boundary and corresponds to a zone of cataclastic weakness. The thermodynamic boundary at $20 \mathrm{~km}$ being a limit for brittle failure, the rocks under lower crustal pressure and temperature must exist in pseudo-ductile state making up a granular medium where slip occurs along fragments produced by a great number of small cracks. Cataclastic flow after breakage can occur uniquely by sick-slip mechanism in the frictional regime and by rotation of rock fragments. So, it is a purely mechanic process with no relation to chemical or mineralogical alterations (White et al., 1982).

The idea that the mechanic state of rocks between 20 and $35 \mathrm{~km}$ deep is represented by a network of interconnected small cracks filled with fluid is connected to the observed leap in electrical conductivity (Popov and Shpynev, 1998). Isotherms show an upwarp beneath the rift zone due to conductive and convective heating and the presence of tangential stress that moves the brittle failure limit to shallower depths. Therefore, the depth of the conductor top will depend on PT conditions for brittle failure. We hypothesis that specific rock rheology at these depths can create favorable conditions for accumulation of highly conductive deep fluids. A similar hypothesis of fluids trapped below the brittle-ductile transition zone is described by Simpson (1998).

Some petrologists suggest that fluids in the lower crust are never free but must be taken up in metamorphic reactions, and thus cannot be responsible for enhanced conductivity (Yardley and Valley, 1997). Following many authors and references therein we agree that fluids in the lower crust are thought to be generated by dehydration of hydrated minerals, diffusion of volatile content from mafic magmas, dewatering of subducted or orogenically underthrust sediments, or degassing of the upper mantle in course of the global evolution of the Earth's interior, (Jones, 1992; Simpson, 1998) all these factors together creating the background mantle flow. To our view, meteoric water penetrating to great depths can be an additional feeding source for deep fluids. Possibility for such penetration was shown at the Baikal region by Pinneker and 


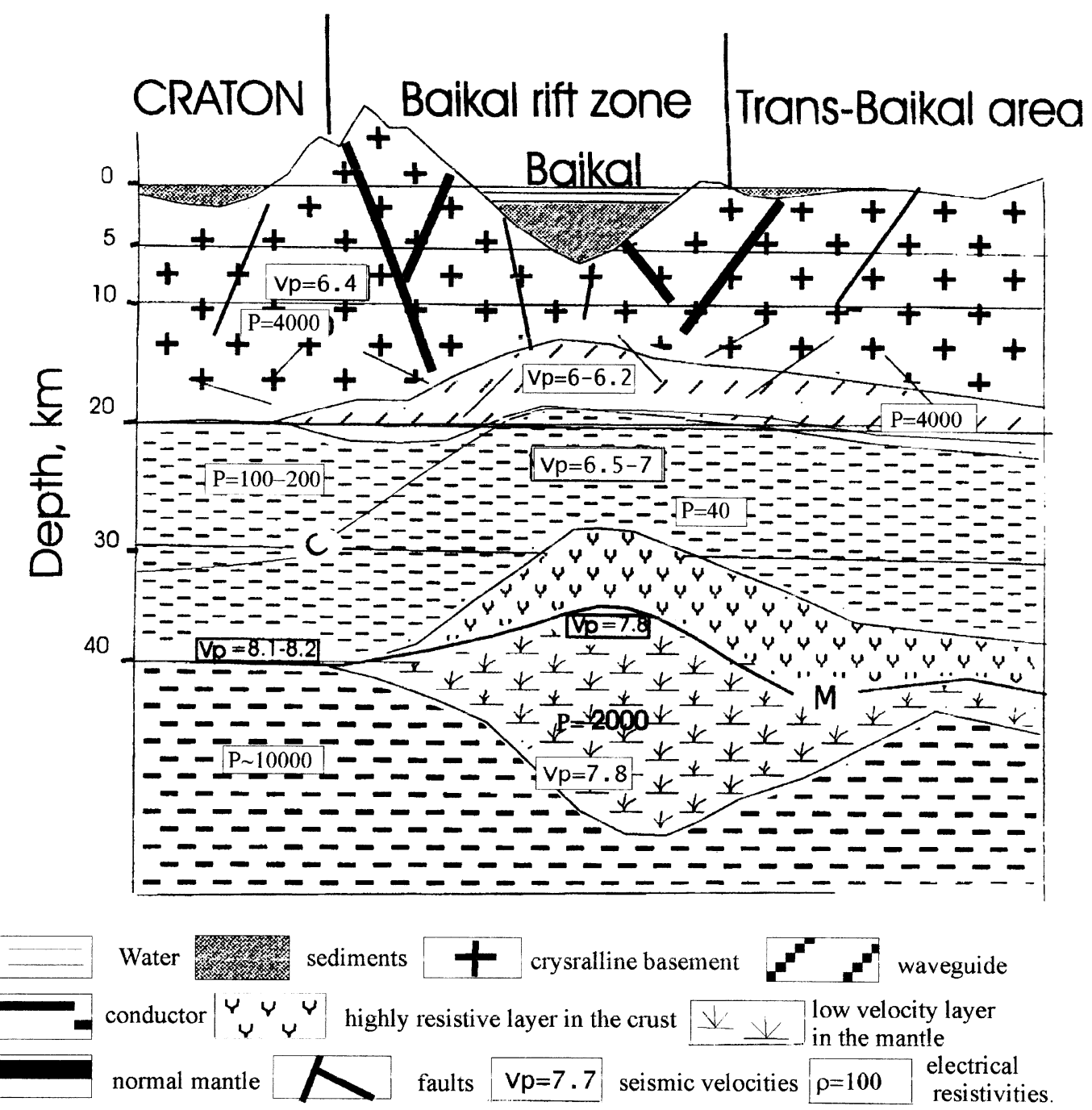

Fig. 7. Generalised seismoelectric model of the crust in the Baikal region. $1=$ water; $2=$ sediments; $3=$ crystalline basement; $4=$ waveguide; $5=$ conductor; $6=$ highly resistive layer in the crust; $7=$ low-velocity layer in the mantle; $8=$ normal mantle; $9=$ faults; $10=$ seismic velocities; $11=$ electrical resistivities.

Popov (1998) and Popov and Shpynev (1998). Brittle failure in the lower crust associated with water infiltration into cracks considerably decreases rock strength and increases electrical conductivity, but without causing meaningful effect on seismic velocities.

The fluid model of the crustal conductive layer beneath the Baikal rift is inconsistent with the idea of spatial coincidence of the conductor and the seismic waveguide. The two do exist in association but at different depths. The typical parameters of low-velocity layer (waveguide) in the Baikal rift zone are the depth interval-11-22 km, thickness $-5 \mathrm{~km}$, shortage of velocity in the layer $0.2-0.3 \mathrm{~km} / \mathrm{s}$. Besides it has an interrupted distribution along the lateral, tectonic character of the medium divided into layers and it has not been identified on the platform (Puzyrev, 1981, 1993). Conductive layer in Baikal region is characterized by thickness of about $20 \mathrm{~km}$, interval of distribution-10-40 km, conductivityfrom 100 to 1000 Siemenses and more, and besides, it is fixed on the platform (Popov, 1989; Popov et al., 1991; Simpson, 1998). Their spatial relationship in the Baikal region is shown in Fig. 7. We suppose that as waveguide as conduc- tor are caused by the zones of tectonic violation (enhanced porosity) but the fluid's presence or abscence within them tells upon these physics parameters in a different way: filling the failures by the fluid leads to the appearence of the conductor but while reconstructing the solidity of the rocks they raise seismic velocities till probably the values closed to undisturbed rock. And vice versa, the absence of the conductive medium (fluid) in failures leads to higher enhanced electric resistance but to lower seismic velocities. It is shown in the work (Berge et al., 1995) that at the saturation of the porous rock of glass by water, velocities $V_{p}$ and $V_{s}$ do not change at all and according to the modelling data (Petkevich and Verbicky, 1965) replacement of air in the pores by the liquid phase leads to increasing of velocity in the medium. At that the velocities changes depend on the correlation of elasticities of the host rock and the water. The most favorable medium for appearance of the conductor is the cataclastic zone, the third layer. In the second zone appearance of waveguides is the most favourable that is caused by the possible existence of the larger and not correlated between each other failures. Such inference follows also from the experi- 
mentally observed fact that rock failure, as well as the onset of dilatancy, decreases seismic velocities and they recover only after cracks and pores become filled with fluid, the regularity basing the diffuse-dilatancy (DD) earthquake model (Nur, 1979). Another proof is in the position of the anomalous layers with respect to each other where waveguides are usually above conductors, the former occurring in the upper crust (Puzyrev, 1981) and the latter being chiefly attributed to the lower crust (Popov, 1989; Popov et al., 1991; Simpson, 1998) (Fig. 7).

Baikal rifting. Proceeding from the foregoing, as well as from the earlier published data, the following typical features can be distinguished in the Baikal rifting: style, mode of expression, and apparently the mechanism, strongly controlled by pre-rift structures, the repeated reactivation of which must be maintained by a local source; concurrency with the India-Eurasia collision that suggests its triggering role for the Cenozoic activity episode; greater "dryness" compared to other active rifts, and lower geophysical contrasts of the deep structure against the surrounding stable areas; vague geophysical expression of the asthenosphere and discord among different methods on the position of its top; the absence of prominent subasthenospheric geophysical anomalies beneath the rift that rules out the existence of a hot spot as a source of tectonic activity; isolation form the world rift system.

Based on the available geological, geophysical and tectonic data, we hypothesis that the excitating source of heat occurs not under the rift zone but beneath the thick insulating continental lithosphere of the adjacent Siberian craton. Due to evident downward increase in thermal conductivity at the account of additional heat transfer by radiation and convection (a realistic absorptivity of $\epsilon=10$ (Stacey, 1968) implies radiative conductivity an order of magnitude higher than the phonon one at $T=1700-1800^{\circ} \mathrm{C}$ ), the inflow of abyssal heat exceeds its slower outflow through the overlying cratonic lithosphere beneath which the extra heat will thus accumulate (Popov, 1990; Popov et al., 1991). Structural data (Melnikov et al., 1994) attest that the Sayan-Baikal area has evolved in a setting of active continental margin since the Late Paleozoic. The Late Paleozoic, Mesozoic, and Cenozoic stages of quiescence and tectonic activity can make up a basis for geothermal modelling of the Earth's interior heating and cooling cycles where the episodes of activity correspond to cooling and the quiescence to accumulation of thermal energy and heating of the lithospheric mantle. After each activity cycle the asthenospheric top subsides due to crystallization of its upper portion at the account of higher solidus temperatures associated with fluid discharge. Each cycle of activity is preceded by intraplate collisions (Khain, 1984). Namely, the Baikal rifting can have been triggered by the India-Eurasia collision (Molnar and Tapponnier, 1975) that reactivated the pre-existing zones of lithospheric weakness and induced convective heat transfer from beneath the cratonic lithosphere towards its anisotropic margin.

Repeated tectonomagmatic reactivation of the cratonic margin, as a consequence of convective flow around the craton root (Popov, 1990; Popov et al., 1991), must be reflected in relic inhomogeneities in the mantle, that can explain the seismic layering of the Siberian Platform evidenced by DSS data (see Fig. 2 and Egorkin et al. (1984)). Then, it can be hypothesized that the low velocity layers in the lithosphere of the Siberian Platform are fossilized past levels of the asthenosphere that had repeatedly subsided to greater depths with each ensuent cycle of activity. The uppermost asthenosphere must contain the greatest amount of low-melting and fluid components, some portion of which remains stored in rocks after convection ceases. Rocks can keep their subsolidus there even at normal temperatures due to temperature contrast between anhydrous and water-saturated rocks.

The results of seismic tomography and SKS splitting measurements that showed anisotropic mantle along the profile across the Baikal rift zone, Trans-Baikal region and a part of the Siberian craton (Gao et al., 1994, 1997) provide a support for the idea of mantle flow from beneath the cratonic lithosphere in the study region. Analysis of the seismic anisotropy in the Baikal-Mongloia province (Gao et al., 1997) showed that fast directions in the central segment of the Baikal rift are distributed either roughly parallel or perpendicular to the NE rift strike, and only the rift orthogonal fast direction is observed in the neighboring Siberian Platform and northern Mongolian fold belt. Gao et al. (1997) attribute the combination of rift-parallel and rift-orthogonal directions in the immediate vicinity of the rift to joint effect of aligned fast axes of olivine crystals in peridotite (lattice preferred orientation) and of oriented magma-filled cracks, but are however not sure in resolving between fossil anisotropy, recent mantle flow, or aligned cracks. Note that the rift-perpendicular fast directions are on a considerable extent of the profile attributed to the craton (Gao et al., 1994, 1997). Inasmuch as the analyzed seismic waves represent the mantle till a depth of $250 \mathrm{~km}$, they bear information on the solid cratonic lithosphere. It means that the observed olivine alignment on this region can be fossil. Away from the rift, changes in fast direcions can be due to microplate motions. Figures 1 and 6 show SKS fast polarization directions in comparison with the direction of plate motions according to Zonenshain et al. (1979). The interpretation results can be considered in fairly good agreement with regard to poor resolution of geological methods for constraining plate motions.

\section{Conclusion}

Magnetotelluric data with their results of other geophysical, seismological and petrological studies, provided a threedimensional modelling of the deep structure of the Baikal, region and to unders of the origin of electrical conductivity anomalies in the middle and lower crust.

Recent seismotectonic activity is evident in geoelectric profiles across the Baikal region and Mongolia (Popov et al., 1993) through enhanced electrical conductivity at the crust and the upwarp of the crustal conductor top. To our view the nature of the conductor is closely related to geodynamics.

In terms of the tectonic nature of seismic reflections, the observed seismic layering of the crust can be attributed to its differentiated response to external tectonic stresses. The geoelectric profile has been produced by downward variation of the rock rheology and the effect of fluids. Some specific rheology at the respective depths creates conditions favorable for accumulation of highly conductive deep fluids compared with a background convective flow of material. 
The asthenosphere cannot be unambiguously detected by magnetotelluric soundings, and was determined on the basis of synthetic inversion of data on Rayleigh surface waves, DSS, and mantle xenoliths thermobarometry. To our view, the origin and evolution of the Baikal rift can be explained in terms of reactivation of a pre-existing lithospheric inhomogeneity between the Siberian craton and the Sayan-Baikal fold area. Therefore, it is another episode of repeated tectonic activity induced by convective mantle flow from beneath the craton to its margins where the India-Eurasia plate collision played a triggering role. The general evolutional scenario and the structural pattern of the Baikal rift has been controlled by interference of the regional and transcontinental stress fields, the former being produced by the mantle flow and the latter associated with the India-Eurasia collision. The major regional anisotropy between the craton and the fold area has been reflected in the asymmetric structure of the Baikal rift basin, the largest basin in the rift system.

Acknowledgments. The research was supported by the Russian Foundation of Basic Research, grant 98-05-64213. We thank T. I. Perepelova for her assistance in translations.

\section{References}

Baisarovich, M. N., M. A. Borodulin, A. G. Nasad, A. M. Stovas, and A. N. Razvalov, Some problems of studies of the crust and upper mantle by seismic reflection (common-depth-point technique), Bulletin of the Ural Regional Geological Committee, 1, 32-36, 1992 (in Russian).

Berdichevsky, M. N., L. L. Vanyan, and A. V. Kashurnikov, The Baikal rift zone: Magnetotelluric arbitration of geodynamic models, in The 14th Workshop on Electromagnetic Induction, Book of Abstracts, 109 pp., Vergiliu Publishers, Bucharest, 1998.

Berge, P. A., B. P. Bonner, and J. G. Berryman, Ultrasonic velocity relationships for sandstone analogs Mane from used glass beads Geophysics, 60(1), 108-119, 1995.

Christensen, N. I. and D. L. Szymanski, Origin of reflections from the Brevard Fault Zone, J. Geophys. Res., 93(B2), 1087-1102, 1988.

Egorkin, A. B., S. K. Zuganov, and N. M. Tchernyshov, Proceedings of the 27-th IGC, Geophysics, 8, 27-42, Nauka, Moscow, 1984 (in Russian).

Fanke, W., R. K. Bortfeld, and M. Brix, Crustal structure of the Rhenish Massif: results of deep seismic reflection lines DEKORP 2-North and 2-North-Q, Geol. Rundsch., 79(3), 523-566, 1990.

Fyfe, W. S., N. J. Price, and A. B. Thompson, Fluids in the Earth's Crust, 385 pp., Elsevier, Amsterdam-Oxford-New York, 1978.

Gao, S., P. M. Davis, H. Liu, P. D. Slack, Yu. A. Zorin, V. V. Mordvinova, V. M. Kozhevnikov, and R. P. Meyer, Seismic anisotropy and mantle flow beneath the Baikal rift zone, Nature, 371, 149-151, 1994.

Gao, S., P. M. Davis, H. Liu, P. D. Slack, A. W. Rigor, Yu. A. Zorin, V. V. Mordvinova, V. M. Kozhevnikov, and N. A. Logatchev, SKS splitting beneath continental rift zones, J. Geophys. Res., 102, 22781-22797, 1997.

Jones, A. G., In the Continental Lower Crust, edited by D. M. Fountain, R. J. Arculus, and R. W. Kay, pp. 81-143, Elsevier, 1992.

Jones, T. D. and A. Nur, The nature of seismic reflections from deep crustal fault zones, J. Geophys. Res., 89(B5), 3153-3167, 1984

Khain, V. E., Geosyncline belts on continental margin: comparison of evolutional features, Proc. 27-th IGC, book 7 (Tectonics), Moscow, pp. 60-63, 1984 (in Russian).

Kiselev, A. I. and A. M. Popov, Asthenospheric diapir beneath the Baikal rift: petrological constraints, Tectonophysics, 208, 287-295, 1992.

Kopnichev, Yu. F., New data on the structure of the upper mantle of the Baikal rift zone, Doklady RAN, 325(5), 944-949, 1992.

Kozhevnikov, V. M., Dispersion of Rg surface waves and the lithospheric structure of the Siberian Platform, Izv. Akad. Nauk SSSR, Ser. Fizika Zemli, 6, 48-56, 1987.

Krylov, S. V., S. I. Golenetsky, and G. V. Petrik, Correlation of seismological data and DSS and the structure of the upper mantle in the Baikal rift zone, Geologia e Geofizika, 12, 61-67, 1974 (in Russian).

Leonov, M. G., Tectonic criteria for interpretations of seismic reflectors in the lower continental crust, Geoteknonika, 5, 4-15, 1993 (in Russian).

Melnikov, A. I., A. M. Mazukabzov, E. V. Sklyarov, and E. P. Vasiliev,
Baikal rift basement: structure and tectonic evolution, Bull. Centres Rech. Explor. Prod. Elf Aquitaine, 18(1), 99-122, 1994.

Molnar, P. and P. Tapponnier, Cenozoic etctonics of Asia: effects of a continental collision, Science, 109, 419-426, 1975.

Nikolaevsky, V. N., Dilatancy rheology of the lithosphere and tectonic stresses, in Main Problems of Seismotectonics, edited by G. P. Gorshkov, pp. 51-68, Nauka, Moscow, 1986 (in Russian).

Nikolaevsky, V. N. and V. I. Sharov, Faults and the mechanism of tectonic layering of the crust, in Mathematical and Experimental Methods in Fault Tectonics, edited by M. V. Rats, pp. 38-46, 1986 (in Russian).

Nur, A., Dilatancy, pore fluids and premonitory variations of fs/tp travel times, Bull. Seismol. Soc. Amer., 62, 1217-1222, 1979.

Pavlenkova, N. I., 1996. Evolution of Views of Seismic Models of the Crust, pp. 11-19, Geofizika, Moscow, (in Russian).

Pavlenkova, N. I. and V. V. Belousov, General structural features of lithosphere of the USSR territory, in Deep Structure of the USSR Territory, edited by V. V. Belousov, pp. 192-208, Nauka, Moscow, 1992 (in Russian).

Petkevich, G. E. and T. Z. Verbicky, Kiev, Research of elastic propeties of porous geologica mediums containing liquids, 1965 (in Russian).

Pinneker, E. V. and A. M. Popov, On the depth of penetration of surface water into the crust (on the example of the Baikal region), Doklady RAN, 359(3), 397-400, 1998.

Popov, A. M., Results of deep MT studies in light of data of other geophysical methods in the Baikal region, Izv. Akad. Nauk SSSR, Ser. Fizika Zemli, 8, 31-37, 1989.

Popov, A. M., A Deep Geophysical Study in the Baikal Region, Pageoph, 134(4), 575-587, 1990.

Popov, A. M. and G. B. Shpynev, The effect of the Lake Baikal water regime on the crustal electrical conductivity in the Baikal rift zone, Izv., Physics of the Solid Earth, 34(6), 476-485, 1998.

Popov, A. M., A. I. Kiselev, and S. V. Lepina, Magnetotelluric stuides in the Baikal region, deep structure and rifting mechanism, Geologia $i$ Geofizika, 4, 106-117, 1991.

Popov, A. M., A. B. Baduev, Yu. V. Kuzminykh, A. Amar, and A. GunchinIsh, Results of magnetotelluric soundings in West Mongolia, Izv. Akad. Nauk SSSR, Ser. Fizika Zemli, 5, 49-57, 1993.

Puzyrev, N. N., (ed.), The Interior of Baikal from Seismic Data, 105 pp., Nauka, Novosibirsk, 1981. (in Russian).

Puzyrev, N. N., (ed.), Detailed Seismic Researche of the Lithosphere on Sand P-Waves, 199 pp., Nauka, Novosibirsk, 1993 (in Russian).

Reston, T. J., Evidence for shear zones in the lower crust offshore Britain, Tectonics, 7(5), 929-945, 1988.

Rogozhina, V. A. and V. M. Kozhevnikov, An Area of Anomalous Mantle Beneath the Baikal Rift, 104 pp., Nauka, Novosibirsk, 1979 (in Russian).

Shchukin, Yu. K., Geophysical studies of seismically hazardous zones of the crust in the USSR territory, in Main Problems of Seismotectonics, edited by V. V. Belousov, pp. 10-24, Nauka, Moscow, 1986 (in Russian).

Sibson, R. N., Fault rocks and fault mechanisms, J. Geol. Soc., 133, 191213, 1977.

Sidorenko, S. A. and A. V. Sidorenko, Organic Matter in Precambrian Metasediments, 115 pp., Nauka, Moscow, 1975 (in Russian).

Simpson, F., Stress and seismicity in the lower continental crust: a challenge to simple ductility and implications for electrical conductivity mechanisms, A review paper, in The 14th Workshop on Electromagnetic Induction, Book of Abstracts, pp. 215-228, Vergiliu Publishers, Bucharest, 1998.

Stacey, F., Energy balance of mantle convection, Tectonophysics, 5, 441452, 1968.

Vanyan, L. L., M. N. Berdichevsky, N. D. Vasin, and B. A. Okulessky, On the normal geoelectric profile, Izv. Akad. Nauk SSSR, Ser. Fizika Zemli, 2, 73-76, 1980.

Vinnik, L. P., G. L. Kosarev, V. V. Mordvinova, S. I. Oreshin, and A. V. Treusov, The Baikal rift: hypotheses and seismic data, Proc. Earth Sciences on the eve of XXI century, Book of Abstracts, Moscow, November 11-14, 1997, p. 5, 1997 (in Russian).

White, S. H., D. J. Evans, and D. L. Zhong, Fault rocks of the Moine Thrust zone: microstructures and textures of selected mylonites, Text. and Microstruct., 5, 33-61, 1982.

Yardley, B. W. D. and J. W. Valley, The petrologic case for a dry lower crust, J. Geophys. Res., 98(B9), 12173-12185, 1997.

Zhang, Yu. S. and T. Tanimoto, High-resolution global upper mantle structure and plate tectonics, J. Geophys. Res., 96, 9397-9823, 1993.

Zonenshain, L. P., L. A. Savostin, L. A. Misharina, and N. V. Solonenko, Geodynamics of the Baikal rift zone and plate tectonics of Inner Asian, in 
Geological and Geophysical Underwater Studies of Lake Baikal, edited by L. P. Zonenshain, pp. 157-202, Institute of Oceanology, Moscow, 1979 (in Russian)

Zorin, Yu. A., V. M. Kozhevnikov, M. R. Novoselova, and E. Kh. Turutanov, Thickness of the lithosphere beneath the Baikal rift zone and adjacent regions, Tectonophysics, 168, 327-337, 1989.

Zorin, Yu. A., M. R. Novoselova, E. Kh. Turutanov, and V. M. Kozhevnikov, Structure of the lithosphere in the Mongolia-Siberian mountainous province, J. Geodyn., 11, 327-342, 1990.

Zorin, Yu. A., V. G. Belichenko, E. Kh. Turutanov, A. M. Mazukabzov, E. V.
Sklyarov, and V. V. Mordvinova, The East Siberia Transect, Inter. Geol. Rev., 37, 154-175, 1995.

Zverev, S. M. and I. P. Kosminskaya, (eds.), Seismic Models of the Lithosphere of Major Geological Structures of the USSR Territory, $184 \mathrm{pp}$. Nauka, Moscow, 1980 (in Russian).

A. M. Popov (e-mail: popov@earth.crust.irk.ru), A. I. Kiselev, and V. V. Mordvinova 